"This is the peer reviewed version of the following article: Does type 1 diabetes alter post-exercise thermoregulatory and cardiovascular function in young adults? McGinn R, Carter MR, Barrera-Ramirez J, Sigal RJ, Flouris AD, Kenny GP. Scand J Med Sci Sports. 2015 Oct;25(5):e504-14. doi: 10.1111/sms.12344. Epub 2014 Dec 8, which has been published in final form at https://doi.org/10.1111/sms.12344.

This article may be used for non-commercial purposes in accordance with Wiley Terms and Conditions for Use of Self-Archived Versions."

\title{
Does Type 1 Diabetes alter postexercise thermoregulatory and cardiovascular function in young adults?
}

Running Title: Postexercise responses in Type 1 Diabetes

Ryan McGinn ${ }^{1}$, Michael R. Carter ${ }^{1}$, Juliana Barrera-Ramirez ${ }^{1}$, Ronald J. Sigal ${ }^{2}$, Andreas D. Flouris ${ }^{3}$ and Glen P. Kenny ${ }^{1}$

\footnotetext{
${ }^{1}$ Human and Environmental Physiology Research Unit, University of Ottawa, Ottawa, ON, Canada; ${ }^{2}$ Departments of Medicine, Cardiac Sciences and Community Health Sciences, Faculties of Medicine and Kinesiology, University of Calgary, Calgary, AB, Canada; ${ }^{3}$ FAME Laboratory, Department of Exercise Science, Trikala, Greece, 42100.
}

Key words: sweating; skin blood flow; postexercise hypotension; hyperthermia

\author{
Address for correspondence: \\ Dr. Glen P Kenny \\ University of Ottawa, \\ School of Human Kinetics, \\ 125 University, Room 367 \\ Montpetit Hall \\ Ottawa, Ontario, Canada \\ K1N 6N5 \\ (613) 562-5800 ext. 4282 \\ (613) 562-5149 (fax) \\ email: gkenny@uottawa.ca
}




\section{ABSTRACT}

Recent data demonstrated that individuals with Type 1 Diabetes (T1DM) exhibit impaired

49 sweating and increased rectal temperature (i.e., heat storage) during exercise compared to healthy

50 Controls. Our purpose in this study was to investigate the consequences of T1DM on postexercise

51 thermal homeostasis. Sixteen participants (8 Controls matched with 8 T1DM) performed 90-min

52 of cycling followed by 60 -min of seated recovery. Esophageal and rectal temperatures, sweating

53 (forearm, chest, and upper back), skin blood flow [forearm and upper back; presented as cutaneous

54 vascular conductance $(\mathrm{CVC})]$, and blood pressure (MAP) were measured at baseline and

55 throughout recovery. Esophageal temperature was similar during baseline and recovery between

56 groups $(\mathrm{P}=0.88)$. However, rectal temperature was elevated in our T1DM group throughout

57 recovery $(\mathrm{P}=0.048)$. Sweating and $\mathrm{CVC}$ were similar between groups at all sites from 10-min

58 postexercise until the end of recovery $(\mathrm{P} \geq 0.16)$. While absolute MAP was similar between groups

$59(\mathrm{P}=0.43)$, the overall decrease in MAP postexercise was greater in Controls from 20-min (T1DM:

$60-8 \pm 5$ vs. Control: $-13 \pm 6 \mathrm{mmHg}, \mathrm{P}=0.03)$ until the end of recovery. We conclude that despite

61 increased heat storage during exercise, individuals with T1DM exhibit a similar suppression in

62 heat loss to their healthy counterparts during recovery. 
It has been well established that the postexercise period is associated with substantial perturbations to thermoregulatory control in healthy individuals as demonstrated by a sustained

67 elevation in core body and muscle temperatures (Kenny et al. 2008). This persistent hyperthermia

68 is the result of rapid reductions in heat loss responses (i.e., skin blood flow and sweating) towards

69 baseline levels during the early stages (within $\sim 20$ minutes) of recovery. While exercise is often

70 prescribed as a key component to the management of Type 1 Diabetes Mellitus (T1DM) (Chimen

71 et al. 2012), the impact of exercise on thermoregulatory control in these individuals has not been

72 well examined. To date, research has demonstrated that local skin blood flow and sweating may

73 be impaired in otherwise healthy individuals with T1DM (Yardley et al. 2013). In fact, a recent

74 study reported that a group of individuals with T1DM had a lower capacity to dissipate heat as

75 evidenced by an attenuated local sweating response (albeit exhibiting regional differences) (Carter

76 et al. 2014). These impairments were paralleled by greater heat storage in individuals with T1DM

77 compared to healthy counterparts as evidenced by greater rectal temperature following 90-min of

78 continuous incremental exercise at fixed rates of metabolic heat production. However, it remains

79 unclear whether these impairments in heat loss persist into the postexercise period.

80 In healthy individuals, the disturbance in postexercise thermoregulatory control is

81 paralleled by alterations in cardiovascular function, commonly characterized by a rapid reduction

82 in mean arterial pressure below baseline levels in the early stages of recovery (Halliwill et al.

83 2013). This phenomenon, known as postexercise hypotension, is generally due to persistent

84 peripheral vasodilation that is not completely offset by increases in cardiac output and can persist

85 for up to 2 hours into recovery (Halliwill 2001). Recent reports have attributed the peripheral

86 vasodilation, and thereby postexercise hypotension, to histamine $\left(\mathrm{H}_{1}\right.$ and $\left.\mathrm{H}_{2}\right)$ receptor activation

87 during recovery (McCord \& Halliwill 2006). While this response has been well examined in 
88 healthy individuals, it is unknown whether those with T1DM would exhibit similar responses

89 during the postexercise period. Considering that individuals with T1DM have been shown to

90 exhibit substantial reductions in postexercise muscle blood flow compared to healthy controls

91 (Menon et al. 1992), it is plausible that postexercise cardiovascular responses in individuals with

92 T1DM may not parallel those of their healthy counterparts.

93 Empirical evidence has identified a possible link between perturbations in postexercise

94 thermoregulatory control and postexercise hypotension (Kenny \& Jay 2013). Specifically, the

95 change in baroreceptor loading status associated with postexercise hypotension has been shown to

96 modulate the level of heat dissipation, and therefore core temperature during recovery. In fact, it

97 is well documented that baroreflex sensitivity can be independently modulated by both exercise

98 and heat stress (Brenner et al. 1997; Parekh \& Lee 2005). Furthermore, Armstrong et al. (2010)

99 recently demonstrated that recovery from exercise-induced heat stress is associated with

100 pronounced reductions from baseline in baroreflex sensitivity in young healthy physically active

101 males. It has been shown that individuals with T1DM without clinically diagnosed autonomic

102 neuropathy exhibit lower levels of baroreflex sensitivity during supine resting (Weston et al. 1998;

103 Weston et al. 1996) relative to their healthy counterparts. However, the extent to which these

104 differences in baroreflex activity exist following exercise in T1DM and how they may affect

105 postexercise thermoregulatory function remains unclear.

106 We have previously examined thermoregulatory responses in detail during exercise in the

107 heat (Carter et al. 2014). The purpose of this study was to evaluate the consequences of an exercise-

108 induced heat stress on postexercise thermoregulatory function, and the relationship to postexercise

109 hemodynamics, in individuals with T1DM. We hypothesized that the impairments in heat

110 dissipation associated with T1DM during exercise would extend into recovery such that despite a 
111 greater end-exercise rectal temperature in T1DM, heat loss responses would be attenuated to a 112 similar extent as Control leading to a sustained state of hyperthermia during the 60-min recovery

113 in individuals with T1DM. We further hypothesized that this response would be paralleled by a 114 greater reduction in baroreflex sensitivity and postexercise hypotension. 


\section{METHODS}

\section{Ethical Approval}

118 The experimental protocol was approved by the University of Ottawa Health Sciences and

119 Science Research Ethics Board, and was in accordance with the Declaration of Helsinki. Written 120 informed consent was obtained from all volunteers prior to their participation in the study.

122 Participants

123 A total of 16 individuals participated in the study. Eight participants (5 males, 3 females)

124 with T1DM were matched for sex, height, body mass, body surface area, body composition, 125 maximal oxygen consumption, and training status with eight healthy Control participants (Table 126 1). Our participants were the same individuals who participated in our previous study (Carter et al. 127 2014). Two T1DM participants (1 male and 1 female) were taking Levothyroxine $\left(0.125 \mathrm{mg} \cdot \mathrm{day}^{-}\right.$

$128{ }^{1}$ and $0.1 \mathrm{mg} \cdot$ day $^{-1}$, respectively) for the treatment of hypothyroidism. The female participant was 129 also taking metformin $\left(500 \mathrm{mg} \cdot \mathrm{day}^{-1}\right)$ for polycystic ovarian syndrome. These medications have 130 not been reported to alter skin blood flow and sweating responses. All participants were non131 smoking and were free from any cardiovascular, respiratory, and other metabolic diseases. [Please insert Table 1 around here]

All participants volunteered for one preliminary and one experimental session. The 136 preliminary session consisted of measurements for body height, mass, and surface area as well as 137 training status and maximal oxygen consumption. Body height was determined using a stadiometer 138 (Detecto, model 2391, Webb City, MO, USA) whereas body mass was measured using a digital 
139 high-performance weighing terminal (model CBU150X, Mettler Toledo, Mississauga, ON, 140 Canada). Body surface area was calculated from body height and mass (Du Bois \& Du Bois 1989). 141 Training status was evaluated by having participants complete both the Kohl's Fitness 142 Questionnaire and the Baecke Sport Index Questionnaire (Baecke et al. 1982; Kohl et al. 1988). 143 Maximal oxygen consumption $\left(\mathrm{VO}_{2 \max }\right)$ was determined by indirect calorimetry (MOXUS system, 144 Applied Electrochemistry, Pittsburgh, PA, USA) during a progressive incremental exercise 145 protocol performed on a constant-load upright cycle ergometer (Corival, Lode BV, Groningen, 146 The Netherlands). The workload was set at $80 \mathrm{~W}$ for $1 \mathrm{~min}$ and participants were instructed to 147 cycle continuously at $\sim 85-90$ rpm (Canadian Society for Exercise Physiology 1986). The work 148 rate was increased by $20 \mathrm{~W}$ every minute thereafter until pedaling cadence of at least $60 \mathrm{rpm}$ could 149 not be maintained.

150 Participants reported to the laboratory between $7 \mathrm{~h} 00$ and $11 \mathrm{~h} 00$ for the experimental 151 session. The participants were asked to drink $500 \mathrm{~mL}$ of water the night before, as well as the 152 morning of the experimental session and to refrain from alcohol, caffeine, and exercise for 24 153 hours prior to experimentation. Participants with T1DM were instructed to take their normal bolus 154 of insulin adjusted for exercise and eat a normal breakfast prior to arriving at the laboratory. Upon 155 arrival, participants provided a urine sample and a nude body mass measurement before changing 156 into shorts, sandals, and a sports bra for females. Urine specific gravity was assessed in duplicate 157 using a refractometer (Reichert TS 400 total solids refractometer, Reichert Inc., Depew, NY, 158 USA). At this point participants rested supine on a bed while an intravenous catheter was inserted 159 into the left antecubital vein for the collection of blood samples at baseline, end of exercise, and 160 at minute 30 and 60 of recovery. Participants subsequently sat upright for a 60 -min instrumentation 
161 period in temperate conditions $\left(\sim 24^{\circ} \mathrm{C}\right)$ before moving to an environmental chamber regulated at $16235^{\circ} \mathrm{C}$ and $20 \%$ humidity for a 30 -min adaptation period.

163 Figure 1 depicts a detailed schematic of the protocol. Following the adaptation period, 30-

164 min of baseline data collection ensued. Thereafter, participants performed 90-min of continuous

165 incremental exercise on a semi-recumbent cycle ergometer. The exercise intensity was set at

166 progressively greater rates of metabolic heat production of 200,250 , and $300 \mathrm{~W} \cdot \mathrm{m}^{-2}$ of body

167 surface area for 30-min each. Participants with T1DM experiencing capillary blood glucose $<4.5$

$168 \mathrm{mmol} \cdot \mathrm{L}^{-1}$ were supplemented with glucose (i.e., Gatorade) as a safety measure. Consequently, each

169 participant with T1DM performed the experimental session prior to the matched Control so that

170 both participants could be given the same amount of Gatorade at the same time point. Six of eight

171 individuals with T1DM required glucose supplementation during exercise. The exercise bout was

172 immediately followed by a 60 -min recovery period in the semi-recumbent position. Following the

173 experimental protocol, participants remained seated for a period of local heating to assess maximal

174 skin blood flow. The local skin heaters were heated to $42^{\circ} \mathrm{C}$ for an initial 15 -min and subsequently

175 to $44^{\circ} \mathrm{C}$ for an additional 30 -min until a stable plateau of skin blood flow was observed for at least

176 5-min. A final nude body mass measurement and urine sample were obtained at the end of the 177 experimental session.

178

179

Measurements

Esophageal and rectal temperatures were measured using a pediatric thermocouple probe

181 of $\sim 2 \mathrm{~mm}$ in diameter (Mon-a-therm, Mallinckrodt Medical Inc., St. Louis, MO, USA) inserted 40

$182 \mathrm{~cm}$ past the entrance of the nostril and $12 \mathrm{~cm}$ pas the anal sphincter, respectively. Skin temperature

183 was measured at four sites using thermocouples (Concept Engineering, Old Saybrook, CT, USA) 
184 attached to the skin with surgical tape. Mean skin temperature was subsequently calculated using

185 a four-point weighting of regional proportions as previously determined (Ramanathan 1964): chest

$186(30 \%)$, biceps $(30 \%)$, calf $(20 \%)$, and quadriceps $(20 \%)$. Temperature data were collected using

187 an HP Agilent data acquisition module (model 3497A; Agilent Technologies Canada Inc.,

188 Mississauga, ON, Canada) every 15 seconds. Data were simultaneously recorded and displayed in

189 spreadsheet format on a personal computer with LabVIEW software (Version 7.0, National 190 Instruments, TX, USA).

191 Local sweat rate was measured as described previously (Carter et al. 2014) on the mid192 anterior forearm, upper back (superior trapezius), and chest (medial to the nipple) on the left side 193 using capsules attached to the skin with adhesive rings and topical skin glue (Collodian HV, 194 Mavidon Medical products, Lake Worth, FL, USA). Local sweat rate was calculated using the 195 difference in water content from the effluent and influent air multiplied by the flow rate and 196 normalized for the skin surface area under the capsule, presented in $\mathrm{mg} \cdot \mathrm{min}^{-1} \cdot \mathrm{cm}^{-2}$. Local skin 197 blood flow was estimated at $32 \mathrm{~Hz}$ using laser-Doppler velocimetry (PeriFlux System 5000, 198 Perimed AB, Stockholm, Sweden) adjacent to the sweat capsules on the mid-anterior forearm and 199 upper back (superior trapezius) as previously described (Carter et al. 2014). Cutaneous vascular 200 conductance (CVC) was subsequently calculated from the ratio of skin blood flow (perfusion units) 201 to mean arterial pressure and presented as a percentage of maximum, as determined during local 202 heating.

203 Heart rate was monitored, recorded every 15 seconds, and stored using a Polar coded 204 WearLink and transmitter, Polar RS400 interface, and Polar Trainer 5 software (Polar Electro, Oy, 205 Finland). Mean arterial pressure was determined during baseline and recovery using a Finometer 206 (Finapres Medical Systems, Amsterdam, The Netherlands) from beat-to-beat recording of the right 
middle finger arterial pressure waveform with the volume-clamp method (Penaz 1973) and

208 physiocal criteria (Wesseling et al. 1995). Blood pressure was verified by auditory inspection with

209 an automated monitor (Tango+, SunTech Medical Inc., Morrisville, NC, USA). The Finometer

210 was also used to measure baroreflex sensitivity which expresses the change in inter-beat interval

211 for a simultaneously occurring change in blood pressure and was calculated as previously

212 described in $\mathrm{ms} \cdot \mathrm{mmHg}^{-1}$ (Westerhof et al. 2006). Baroreflex sensitivity is presented every 10 -min

213 throughout recovery as an average of the preceding 3-min.

214 Metabolic energy expenditure was assessed using indirect calorimetry during exercise

215 (Nishi 1981). Expired gas was analyzed for oxygen (error of $\pm 0.01 \%$ ) and carbon dioxide (error

216 of $\pm 0.02 \%$ ) concentrations using electrochemical gas analyzers (AMETEK model S-3A/1 and CD

217 3A, Applied Electrochemistry, Pittsburgh, PA, USA). Prior to each session, gas mixtures of known

218 concentrations $\left(\sim 17 \% \mathrm{O}_{2}\right.$ and $\sim 4 \% \mathrm{CO}_{2}$, balance $\left.\mathrm{N}_{2}\right)$ were used to calibrate the gas analyzers and

219 a $3 \mathrm{~L}$ syringe was used to calibrate the turbine ventilometer (error $\pm 1 \%$ ).

220 An intravenous catheter was inserted, secured in place with a $6 \times 7 \mathrm{~cm}$ film dressing

221 (Tegaderm Film, 3M Health Care, St. Paul, MN, USA), and connected to a Luer-Lock extension

222 (Microbore Extension, Clave ${ }^{\mathrm{TM}}$, Locking Spin Collar, Non-DEHP). Venous blood samples were

223 taken $(\sim 10 \mathrm{~mL})$ during baseline, at the end of exercise, and at $\min 30$ and 60 of recovery. Blood

224 samples were collected into K2 EDTA $^{\mathrm{TM}}$ and Serum ${ }^{\mathrm{TM}}$ vacutainers (BD Vacutainer, Franklin

225 Lakes, NJ, USA) for the determination of plasma volume and osmolality, respectively. Samples in

226 the K2 $\mathrm{EDTA}^{\mathrm{TM}}$ vacutainers were immediately analyzed for hemoglobin $(\mathrm{Hb})$ concentration and

227 hematocrit (Hct) ratio to calculate changes in plasma volume as described previously (Dill \&

228 Costill 1974). Samples in the Serum ${ }^{\mathrm{TM}}$ vacutainers were allowed to sit for 20 -min before being

229 centrifuged. Plasma aliquots were collected, frozen at $-20{ }^{\circ} \mathrm{C}$ and stored at $-70{ }^{\circ} \mathrm{C}$ until analysis of 
230 plasma osmolality using the freezing-point method (Osmometer, Advance Instruments, Norwood, 231 MA, USA).

232 Cardiac output was measured non-invasively during baseline (in triplicate and presented

233 as an average) and at 10-min intervals during recovery using an Innocor ${ }^{\mathrm{TM}}$ inert gas-rebreathing

234 unit (Innovisions, Odense, Denmark) which has been previously validated against the direct Fick

235 method and thermodilution (Peyton \& Thompson 2004). Heart rate and arterial oxygen saturation

236 were measured during each test which consisted of breath-by-breath ergospirometry with 5\%

237 nitrous oxide and 1\% sulphur hexafluoride diluted with ambient air (Ayotte et al. 1970). The

238 participant was asked to breathe through a breathing filter (Pro-Tec Filters, PF30S, 30 mm ports,

239 Odense, Denmark) connected to a 3-way valve, an anti-static rubber bag, and a gas analyzer. Stroke

240 volume was calculated as cardiac output divided by heart rate.

242 Data Analysis

243 All variables were compared between groups (T1DM vs Control) to evaluate the influence

244 of T1DM on the recovery from exercise in the heat. Local sweat rate, CVC, and esophageal, mean 245 skin, and rectal temperatures are presented for the end of exercise (i.e., minute 90 of exercise) as 246 well as in 10-min intervals for the duration of the 60-min recovery. The time constant (tau) for the 247 reduction in sweat rate and skin blood flow was also calculated using an exponential, one-phase 248 association non-linear regression analysis and represented the exponential decay observed during 249 recovery. Mean arterial pressure (absolute and relative change from baseline), baroreflex 250 sensitivity, cardiac output, stroke volume, heart rate, and total peripheral resistance are also 251 presented in 10-min intervals for the duration of the 60-min recovery. Plasma osmolality and 252 venous blood glucose are presented at baseline, end-exercise, and at minutes 30 and 60 of recovery 
253 whereas changes in plasma volume from baseline are presented at the end of exercise, and at

254 minutes 30 and 60 of recovery.

255

256 Statistical Analysis

257 A two-way repeated measures analysis of variance (ANOVA) was conducted to evaluate 258 whether a main effect of time (6 levels: 10, 20, 30, 40, 50, and 60 minutes of recovery) and group

259 (2 levels: T1DM and Control) was present for local sweat rate, CVC, heart rate, mean arterial 260 pressure (absolute and relative change from baseline), esophageal, mean skin, and rectal 261 temperatures, baroreflex sensitivity, cardiac output, stroke volume, and total peripheral resistance.

262 A two-way ANOVA was also conducted with factors of time (4 levels: baseline, end-exercise, and 263 minutes 30 and 60 of recovery) and group (2 levels: T1DM and Control) for plasma osmolality, 264 and venous blood glucose. Finally, a two-way ANOVA was conducted to evaluate changes in 265 plasma volume from baseline with factors of time (3 levels: end-exercise and minutes 30 and 60 266 of recovery). When a significant main effect was observed, post-hoc comparisons were carried out 267 using Student's paired samples $t$-tests corrected for multiple comparisons with the Holm268 Bonferroni procedure. The level of significance for all analyses was set at $\mathrm{P}<0.05$. Curve fitting 269 analysis was performed using GraphPad Prism 5.0 (GraphPad Software, La Jolla, CA, USA). All 270 other statistical analyses were completed using the software package SPSS 21.0 for Windows 271 (IBM Corp. Armonk, NY, USA). Values are presented as mean \pm standard error of the mean unless 272 otherwise indicated.

273

274 


\section{RESULTS}

276 Experimental session

277 No differences were observed between groups for age $(\mathrm{P}=0.685)$, height $(\mathrm{P}=0.377)$, mass $278(\mathrm{P}=0.288)$, body surface area $(\mathrm{P}=0.840)$, maximal oxygen consumption $(\mathrm{P}=0.964)$, or training 279 status (Kohl's score: $\mathrm{P}=0.826$; Baeke's score: $\mathrm{P}=0.458$ ) (see Table 1). No differences were found 280 between groups for metabolic heat production $(\mathrm{P}=0.257)$ or percentage of maximal oxygen 281 consumption $(\mathrm{P}=0.849)$ throughout the exercise bout. Further, urine specific gravity did not differ 282 between groups at the start (T1DM: $1.021 \pm 0.007$; Control: $1.016 \pm 0.006, \mathrm{P}=0.400)$ or end 283 (T1DM: $1.022 \pm 0.005$; Control: $1.017 \pm 0.006, \mathrm{P}=0.180)$ of the experimental session.

Thermoregulatory variables

Core and skin temperatures. Esophageal, mean skin, and rectal temperature responses are

287 depicted in Figure 2. There was a main effect of time observed for esophageal temperature 288 throughout recovery $(\mathrm{P}=0.018)$, but not for group $(\mathrm{P}=0.875)$. Similarly, a main effect of time $289(\mathrm{P}<0.001)$, but not group $(\mathrm{P}=0.484)$ was observed for mean skin temperature postexercise. In 290 contrast, a main effect of time $(\mathrm{P}<0.001)$ and group $(\mathrm{P}=0.048)$ was observed for rectal temperature 291 during recovery. Despite being similar at baseline (T1DM: $36.99 \pm 0.08^{\circ} \mathrm{C}$; Control: $37.07 \pm$ $\left.2920.16^{\circ} \mathrm{C}, \mathrm{P}=0.425\right)$, the increase in rectal temperature during exercise was greater in $\mathrm{T} 1 \mathrm{DM}$ at the 293 end of exercise compared to Control $\left(1.51 \pm 0.15^{\circ} \mathrm{C}\right.$ vs. $1.00 \pm 0.10^{\circ} \mathrm{C}, \mathrm{P}=0.046$, respectively $)$ and 294 remained elevated throughout recovery.

[Please insert Figure 2 around here] 
298 observed at either site (forearm: $\mathrm{P}=0.160$; upper back: $\mathrm{P}=0.652$ ) (see Figure 3). Furthermore, tau

299 for CVC during recovery from exercise was similar between groups at the forearm (T1DM: $21 \pm$

$3007 \mathrm{~min}$; Control: $17 \pm 5 \mathrm{~min}, \mathrm{P}=0.382$ ) and upper back (T1DM: $14 \pm 5 \mathrm{~min}$; Control: $17 \pm 5 \mathrm{~min}$, $301 \mathrm{P}=0.517)$. recovery are depicted in Figure 4. While a main effect of time was observed for local sweat rate at 305 the forearm $(\mathrm{P}=0.002)$, chest $(\mathrm{P}<0.001)$, and upper back sites $(\mathrm{P}=0.006)$, there was no main effect 306 of group during the postexercise period (forearm: $\mathrm{P}=0.752$; chest: $\mathrm{P}=0.702$; upper back: $\mathrm{P}=0.259$ ).

307 This was despite the significantly lower local sweat rate at the end of exercise at the forearm 308 ( $\mathrm{P}=0.029)$ and chest $(\mathrm{P}=0.047)$ sites in the T1DM group compared to the Control group. Further,

309 the tau value for sweat rate during recovery was similar between groups at the forearm (T1DM:

$31012 \pm 5$ min; Control: $13 \pm 4$ min, $\mathrm{P}=0.856$ ), chest (T1DM: $16 \pm 6$ min; Control: $14 \pm 4$ min,

$311 \mathrm{P}=0.628$ ), and upper back (T1DM: $17 \pm 5 \mathrm{~min}$; Control: $15 \pm 4 \mathrm{~min}, \mathrm{P}=0.660)$. However, it should

312 be noted that the magnitude of decrease in local sweat rate was greater in the Control group at the

313 forearm (T1DM: $0.58 \pm 0.20 \mathrm{mg} \cdot \mathrm{min}^{-1} \cdot \mathrm{cm}^{-2}$; Control: $0.84 \pm 0.20 \mathrm{mg} \cdot \mathrm{min}^{-1} \cdot \mathrm{cm}^{-2}, \mathrm{P}=0.003$ ) and the

314 chest (T1DM: $0.51 \pm 0.14 \mathrm{mg} \cdot \mathrm{min}^{-1} \cdot \mathrm{cm}^{-2}$; Control: $0.85 \pm 0.29 \mathrm{mg} \cdot \mathrm{min}^{-1} \cdot \mathrm{cm}^{-2}, \mathrm{P}=0.035$ ) compared 315 to the T1DM group.

317 Cardiovascular variables.

318 Mean arterial pressure. Postexercise mean arterial pressure exhibited a main effect of time $319(\mathrm{P}=0.047)$, but not group $(\mathrm{P}=0.430)$ (Table 2$)$. However, when presented relative to baseline levels, 320 there was a main effect of time $(\mathrm{P}=0.049)$ and group $(\mathrm{P}=0.024)$ for mean arterial pressure (Figure 
321 5). Despite being similar between groups (T1DM: $-11 \pm 7 \mathrm{mmHg}$; Control: $-11 \pm 6 \mathrm{mmHg}$,

$322 \mathrm{P}=0.953$ ) at 10 -min into recovery, the magnitude of postexercise hypotension became

323 progressively lower in T1DM compared to Control. Specifically, the relative change in mean

324 arterial pressure from baseline levels was reduced in T1DM $(-8 \pm 5 \mathrm{mmHg})$ compared to Control

$325(-13 \pm 6 \mathrm{mmHg}, \mathrm{P}=0.026)$ at 20 -min of recovery, and this difference persisted until the end of the

326 60-min recovery (T1DM: $-1 \pm 3 \mathrm{mmHg}$; Control: $-9 \pm 3 \mathrm{mmHg}, \mathrm{P}=0.002$ ).

[Please insert table 2 and Figure 5 around here]

Stroke volume, heart rate, cardiac output, and total peripheral resistance. Cardiovascular

329 responses are presented in Table 2. During the postexercise period, there was a main effect of time

$330(\mathrm{P}=0.024)$, but not group $(\mathrm{P}=0.719)$ for stroke volume such that stroke volume was reduced from

331 baseline levels at 10-min of recovery (T1DM: $-20 \pm 5 \mathrm{~mL}$; Control: $-21 \pm 6 \mathrm{~mL}, \mathrm{P}<0.001)$ and

332 progressively returned towards baseline levels. Similarly, there was also a main effect of time

$333(\mathrm{P}<0.001)$, but not group $(\mathrm{P}=0.382)$ for heart rate during recovery. Heart rate was elevated from

334 baseline levels at 10-min into recovery (by T1DM: $34 \pm 5$ bpm; Control: $29 \pm 8$ bpm, $\mathrm{P}<0.001$ )

335 and progressively decreased towards baseline levels. In parallel with these observations, cardiac

336 output exhibited a main effect of time $(\mathrm{P}<0.001)$, but not group $(\mathrm{P}=0.378)$ during recovery.

337 Specifically, cardiac output was increased at 10-min postexercise (by T1DM: $1.1 \pm 0.4 \mathrm{~L} \cdot \mathrm{min}^{-1}$;

338 Control: $\left.1.2 \pm 0.3 \mathrm{~L} \cdot \mathrm{min}^{-1}\right)$ compared to baseline levels $(\mathrm{P}<0.023)$. Finally, there was also a main

339 effect of time $(\mathrm{P}<0.001)$, but not group $(\mathrm{P}=0.210)$ observed for total peripheral resistance during

340 recovery such that resistance was reduced at 10 -min into recovery (by T1DM: $-3 \pm 1 \mathrm{mmHg} \cdot \mathrm{L}^{-}$

$34{ }^{1} \cdot \mathrm{min}^{-1}$; Control: $\left.-3 \pm 1 \mathrm{mmHg} \cdot \mathrm{L}^{-1} \cdot \mathrm{min}^{-1}\right)$ compared to baseline levels $(\mathrm{P} \leq 0.001)$ and progressively

342 increased until the end of recovery. 
344 observed for baroreflex sensitivity during recovery (Figure 5). While no differences were observed

345 between T1DM $\left(11 \pm 3 \mathrm{~ms} \cdot \mathrm{mmHg}^{-1}\right)$ and Control $\left(12 \pm 4 \mathrm{~ms} \cdot \mathrm{mmHg}^{-1}, \mathrm{P}=0.485\right)$ at baseline, the

346 reduction in baroreflex sensitivity was exacerbated from 10 min into recovery (T1DM: $2.9 \pm 0.5$

$347 \mathrm{~ms} \cdot \mathrm{mmHg}^{-1}$; Control: $5.3 \pm 1.0 \mathrm{~ms} \cdot \mathrm{mmHg}^{-1}, \mathrm{P}=0.003$ ) until the end of the 60 min recovery

348 (T1DM: $5.7 \pm 1.0 \mathrm{~ms} \cdot \mathrm{mmHg}^{-1}$; Control: $8.4 \pm 1.3 \mathrm{~ms} \cdot \mathrm{mmHg}^{-1}, \mathrm{P}=0.011$ ).

350 Blood glucose, plasma osmolality, and changes in plasma volume.

351 The responses for blood glucose, plasma osmolality, and the changes in plasma volume are

352 presented in Table 3. We observed a main effect of time $(\mathrm{P}=0.035)$ and group $(\mathrm{P}=0.020)$ for venous

353 blood glucose throughout the experimental session such that blood glucose was increased in T1DM

$354\left(9.9 \pm 1.0 \mathrm{mmol} \cdot \mathrm{L}^{-1}\right)$ compared to Control $\left(5.3 \pm 0.2 \mathrm{mmol} \cdot \mathrm{L}^{-1}, \mathrm{P}=0.004\right)$ only at baseline. Plasma 355 osmolality and changes in plasma volume also exhibited a main effect of time $(\mathrm{P}<0.001)$, but not 356 group (plasma osmolality: $\mathrm{P}=0.650$; plasma volume: $\mathrm{P}=0.189$ ) throughout the experimental 357 session. 


\section{DISCUSSION}

In this study, we simultaneously assessed the thermoregulatory and cardiovascular

362 responses during recovery from exercise in individuals with T1DM. Contrary to our hypothesis,

363 there were no differences in the level of suppression in postexercise skin blood flow or sweating.

364 This was paralleled by similar esophageal and mean skin temperatures between T1DM and

365 Control, thereby indicating a similar level of heat stress. However, we show that the rate of

366 suppression in sweating at the forearm and chest sites is greater in the Control group. The

367 postexercise cardiovascular responses were consistent with our hypothesis such that we observed

368 a greater attenuation in baroreflex sensitivity in individuals with T1DM relative to Control. In

369 addition, the reduction in postexercise mean arterial pressure relative to baseline resting values

370 was less pronounced in individuals with T1DM. Taken together, our findings indicate that

371 individuals with T1DM do not exhibit marked differences in thermoregulatory or cardiovascular

372 control following prolonged exercise-induced heat stress despite experiencing a greater degree of

373 heat storage as defined by a significantly higher end-exercise rectal temperature.

\section{Thermoregulatory control}

376 The only study to date that has examined postexercise skin blood flow in individuals with

377 T1DM (Stapleton et al. 2013) reported no differences in skin blood flow at the forearm throughout

378 the exercise (i.e., $60 \mathrm{~min}$ at $200 \mathrm{~W} \cdot \mathrm{m}^{-2}$ or subsequent 60 -minute recovery. These findings are

379 consistent with our results at both the forearm and upper back sites such that we observed no

380 differences between groups despite a higher exercise intensity during the final hour of exercise

381 (i.e., $\left.\geq 250 \mathrm{~W} \cdot \mathrm{m}^{-2}\right)$ and a greater level of hyperthermia (a $0.6^{\circ} \mathrm{C}$ greater increase in end-exercise

382 rectal temperature in our T1DM group) achieved in the current study. However, these observations

383 contrast those of prior studies reporting impairments in skin vascular function associated with 
384 T1DM as assessed through pharmacological stimuli (Katz et al. 2001; Khan et al. 2000). Thus, the

385 altered skin blood flow response induced by the administration of exogenous vasoactive agents 386 may not reflect changes in skin blood flow during or following exercise in the heat. Taken together, 387 our findings indicate that the similarity in skin blood flow responses between T1DM and healthy 388 individuals are not limited to the exercise period (Carter et al. 2014; Stapleton et al. 2013), but 389 rather are also observed during the subsequent recovery.

Although we did not observe any differences in skin blood flow between groups, we show

391 that the end-exercise sweating response was attenuated at the forearm and chest skin sites in our

392 T1DM participants. Of note, however, regional differences were observed such that there was no

393 difference in end-exercise sweat rate at the upper back. Although sweat rate was reduced at the

394 end of exercise in the T1DM group, we observed similar tau values between groups despite a 395 smaller amplitude of change (i.e., a smaller decrease) in sweat rate for our T1DM group at the 396 forearm and chest sites. While this more rapid suppression of sweating could be explained by a 397 reduced thermal load defined by a lower end-exercise rectal temperature in the Control group, the 398 lack of a difference in esophageal and/or mean skin temperatures (i.e., thermal drive perceived at 399 the hypothalamus) would suggest otherwise (Figure 2). On the other hand, we did not observe any 400 differences between groups in absolute sweat rate at any of the skin sites throughout the 401 postexercise period which parallels the findings by Stapleton and colleagues (2013) who reported 402 no differences in whole-body heat loss for $60 \mathrm{~min}$ of recovery in habitually active individuals with 403 T1DM.

404 In parallel with the heat loss responses during recovery, both groups showed similar time405 dependent changes in esophageal and mean skin temperatures. In contrast, rectal temperature 406 remained significantly elevated in T1DM participants relative to Controls throughout the recovery 
407 period. It has been argued that esophageal temperature is more reflective of blood temperature, 408 and therefore central brain temperature (Whitby \& Dunkin 1971). As such, esophageal temperature 409 is thought to be the main stimulus driving the activation of thermoeffector activity during heat 410 stress at the level of the hypothalamus (i.e., thermal drive). On this basis, and consistent with prior

411 findings from a whole-body calorimetric perspective (Stapleton et al. 2013), our results would 412 indicate that individuals with T1DM experienced similar thermal drive compared to their healthy 413 Controls and demonstrate a similar rate of heat loss throughout the postexercise period. On the 414 other hand, it has been suggested that rectal temperature more accurately reflects the amount of 415 whole-body heat storage (Jay et al. 2007). As noted, rectal temperature, and therefore body heat 416 storage, was significantly greater in our T1DM group (Figure 2). These differences in rectal 417 temperature between groups may be attributed to altered tissue perfusion [i.e., reduced muscle 418 blood flow (Menon et al. 1992)] in our T1DM group which would ultimately influence heat 419 transfer in the surrounding tissues (i.e., in the rectum). Irrespective of the absolute differences in 420 rectal temperature, the level of heat loss was similar between groups. This corresponded to a 421 similar magnitude of decrease from end-exercise levels between groups over the course of the 60 422 minute recovery (T1DM: $\sim 0.8^{\circ} \mathrm{C}$; Controls: $\sim 0.7^{\circ} \mathrm{C}$ ), thereby indicating that rectal temperature 423 may not be the primary stimulus driving heat loss during recovery. In the context of our 424 observations, further research is required to examine the relationship between regional changes in 425 central and peripheral thermal input, and therefore sensor-to-effector pathways, on heat loss in 426 individuals with diabetes. 
Postexercise hypotension has been shown to be largely mediated by histamine $\left(\mathrm{H}_{1}\right.$ and $\left.\mathrm{H}_{2}\right)$

432 receptor activation causing skeletal muscle vasodilation in healthy individuals (McCord \&

433 Halliwill 2006). We did not observe any differences in absolute mean arterial pressure between

434 groups which were paralleled by similarities in other hemodynamic measures including cardiac

435 output, stroke volume, heart rate, and total peripheral resistance. However, it was noted that the 436 magnitude of hypotension was blunted in our T1DM participants such that blood pressure returned

437 to baseline levels much more quickly compared to the Controls (Figure 5). Considering 438 postexercise hypotension is thought to be largely mediated by skeletal muscle vasodilation

439 (Halliwill et al. 2013), our observations would be explained by previously reported reductions in 440 muscle blood flow associated with T1DM (Menon et al. 1992). Specifically, Menon et al. (1992)

441 observed greater reductions in postexercise muscle blood flow in individuals with T1DM relative

442 to matched healthy adults. The mechanism(s) and potential implications for this response remain

443 unclear. However, it has been shown that individuals with T1DM experience a state of chronic

444 inflammation (King 2008) which may lead to differences in histamine receptor activation.

445 A relationship between persistent postexercise hyperthermia and postexercise hypotension

446 has been postulated such that the postexercise attenuation in heat loss responses of skin blood flow

447 and sweating was the result of a nonthermal baroreflex-mediated suppression (Kenny \& Jay 2013).

448 This hypothesis was supported by reports demonstrating that reversal of baroreceptor unloading

449 (i.e., increases in blood pressure) during the postexercise period resulted in a reversal in the 450 attenuation of heat loss responses paralleled by a more rapid decay in esophageal temperature 451 (Jackson \& Kenny 2003; McInnis et al. 2006). In the present study, absolute mean arterial pressure 452 did not differ between groups; however, we did observe a greater reduction in the magnitude of 
453 postexercise hypotension in participants with T1DM (Figure 5) when compared to Controls. In 454 contrast to previous reports (Jackson \& Kenny 2003), the blunted postexercise hypotension was 455 not associated with a concomitant increase in skin blood flow or sweating. Consequently, further 456 study is warranted to determine whether diabetes can alter the relationship between postexercise 457 heat dissipation and blood pressure regulation.

458 It has also been shown that baroreflex sensitivity is reduced following exercise in healthy 459 adults compared to baseline resting levels (Armstrong, Seely 2010). Consistent with these 460 observations, we showed reductions in postexercise baroreflex sensitivity in both T1DM and 461 Control groups. However, baroreflex sensitivity was impaired to a greater extent in individuals 462 with T1DM during recovery which is consistent with findings reported under resting conditions 463 (Weston, James 1998; Weston, Panerai 1996). Alternatively, recent reports indicate a 464 hypoglycemic episode can be followed by decreases in baroreflex sensitivity and sympathetic 465 activation (Adler et al. 2009; Limberg et al. 2014). Importantly, we supplemented with Gatorade 466 when blood glucose reached $<4.5 \mathrm{mmol} \cdot \mathrm{L}^{-1}$, which was necessary for $75 \%$ (6 of 8 ) of our 467 participants with T1DM during exercise. The consequences of hypoglycemia on cardiovascular 468 and thermoregulatory responses are currently unknown; however, it is possible that the high 469 incidence of lower blood glucose levels (albeit not clinical hypoglycemia) during recovery may 470 present a confounding influence to our measurements of baroreflex sensitivity during recovery.

\section{Considerations}

473 It is important to consider that our findings may only apply to young, otherwise healthy, 474 and active individuals with T1DM. Specifically, our participants with T1DM had good-to475 moderate glycemic control $\left(\mathrm{HbA}_{1 \mathrm{c}}<8.5 \%\right)$ and were habitually active. While these characteristics 
476 were employed to ensure the safety of our participants, it is unclear how individuals with T1DM

477 who are older, less active and with poorer blood glucose control may differ. Considering the

478 reductions to heat loss observed in healthy older adults (Kenny \& Jay 2013), and in view of the

479 impairments to skin blood flow and sweating being exacerbated by higher $\mathrm{HbA}_{1 c}$ and the

480 presence/severity of diabetic neuropathy (Yardley et al. 2013), it seems likely that we would

481 observe a more pronounced impairment in these individuals.

482

483 Perspectives

484 Recent evidence indicates that T1DM is associated with regional sweating impairments at 485 exercise-induced heat loads at $\geq 250 \mathrm{~W} \cdot \mathrm{m}^{-2}$ (i.e., $\sim 55-65 \%$ of maximal oxygen consumption), 486 leading to greater body heat storage (Carter et al. 2014). Thus, otherwise healthy individuals with 487 T1DM may not be at increased risk for heat-related injury during exercise-induced heat loads 488 below $250 \mathrm{~W} \cdot \mathrm{m}^{-2}$ (equivalent to $\sim 55 \%$ of maximal oxygen consumption in our participants). 489 However, increases in metabolic and/or environmental heat loads may present a greater risk for 490 individuals with T1DM who would likely store more heat. In light of our observations that 491 individuals T1DM exhibited a similar reduction in heat loss to their healthy counterparts during 492 recovery despite greater heat storage, they would likely sustain a greater level of hyperthermia. 493 This may have important implications in the context of intermittent work which represents the 494 majority of daily activities. Specifically, the impairments in heat loss associated with T1DM during 495 exercise combined with a similar level of heat loss during recovery would result in individuals 496 with T1DM carrying over a greater level of hyperthermia into subsequent exercise bouts. Studies 497 show that intermittent exercise corresponds to a progressive increase in body heat storage due to 498 the fact that the heat stress is maintained via a continued rapid suppression in heat loss during 
499 recovery (Kenny et al. 2009). The extent to which this may impact individuals with T1DM is

500 unclear; however, given the impairments in heat loss observed during exercise, it is likely that

501 subsequent exercise bouts would result in even greater levels of heat storage. Further research is

502 necessary to evaluate this hypothesis in the context of athletes and workers with T1DM, and to

503 determine the most efficacious work-rest cycles to minimize the risk for heat-related injury.

504 In summary, we show that there are no differences in local skin blood flow or sweating

505 between groups for the duration of the 60-min recovery. We also observed a similar pattern in

506 absolute hemodynamic responses; however, the magnitude of postexercise hypotension was

507 markedly reduced in our participants with T1DM compared to Controls. In addition, a reduction

508 in baroreflex sensitivity during recovery was demonstrated in our T1DM group; albeit this may

509 have been confounded by the high incidence of lower levels of blood glucose during exercise.

510 Therefore, our findings indicate that young adults with T1DM who are otherwise healthy do not

511 appear to exhibit greater perturbations in thermal or hemodynamic responses following exercise. 


\section{ACKNOWLEDGEMENTS}

513 The authors thank all members of the Human and Environmental Physiology Research Unit

514 who assisted with data collection. We would also like to thank all the participants who volunteered

515 for the present study. This data forms part of a larger study and details pertaining to the data during

516 exercise have been published elsewhere (Carter et al, 2014). This research was supported by the

517 Natural Sciences and Engineering Research Council (RGPIN-298159-2009), the Canadian

518 Institutes for Health Research (286363) and Leaders Opportunity Fund from the Canada

519 Foundation for Innovation (funds held by Dr. Glen P. Kenny). Dr. Glen P. Kenny was supported

520 by a University of Ottawa Research Chair. Ryan McGinn was supported by a Queen Elizabeth II

521 Graduate Scholarship in Science and Technology. Juliana Barrera-Ramirez was supported by an

522 Alexander Graham Bell Canada Graduate Scholarship and an Ontario Graduate Scholarship. Dr.

523 Ronald J. Sigal was supported by a Health Senior Scholar award from Alberta Innovates-Health

524 Solutions. 
Adler GK, Bonyhay I, Failing H, Waring E, Dotson S, Freeman R. Antecedent hypoglycemia impairs autonomic cardiovascular function: implications for rigorous glycemic control. Diabetes.

529 2009: 58: 360-366.

530 Armstrong RG, Seely AJ, Kilby D, Journeay WS, Kenny GP. Cardiovascular and thermal 531 responses to repeated head-up tilts following exercise-induced heat stress. Aviat Space Environ 532 Med. 2010: 81: 646-653.

533 Ayotte B, Seymour J, McIlroy MB. A new method for measurement of cardiac output with 534 nitrous oxide. J Appl Physiol. 1970: 28: 863-866.

535 Baecke JA, Burema J, Frijters JE. A short questionnaire for the measurement of habitual physical activity in epidemiological studies. Am J Clin Nutr. 1982: 36: 936.

Brenner IK, Thomas S, Shephard RJ. Spectral analysis of heart rate variability during heat exposure and repeated exercise. Eur J Appl Physiol Occup Physiol. 1997: 76: 145-156. Appraiser Resource Manual. Gloucester, Ontario, Canada: CSEP, 1986:1-32.

Carter MR, McGinn R, Barrera-Rarmirez J, Sigal RJ, Kenny GP. Impairments in local heat loss in Type 1 diabetes during exercise in the heat. Med Sci Sports Exerc. 2014.

543 Chimen M, Kennedy A, Nirantharakumar K, Pang TT, Andrews R, Narendran P. What are the 544 health benefits of physical activity in type 1 diabetes mellitus? A literature review. Diabetologia. 545 2012: 55: 542-551.

546 Dill DB, Costill DL. Calculation of percentage changes in volumes of blood, plasma, and red 547 cells in dehydration. J Appl Physiol. 1974: 37: 247-248.

548 Du Bois D, Du Bois EF. A formula to estimate the approximate surface area if height and weight 549 be known. 1916. Nutrition. 1989: 5: 303-311; discussion 312-303.

550 Halliwill JR. Mechanisms and clinical implications of post-exercise hypotension in humans. 551 Exerc Sport Sci Rev. 2001: 29: 65-70.

552 Halliwill JR, Buck TM, Lacewell AN, Romero SA. Postexercise hypotension and sustained 553 postexercise vasodilatation: what happens after we exercise? Exp Physiol. 2013: 98: 7-18.

554 Jackson DN, Kenny GP. Upright LBPP application attenuates elevated postexercise resting 555 thresholds for cutaneous vasodilation and sweating. J Appl Physiol (1985). 2003: 95: 121-128.

556 Jay O, Gariepy LM, Reardon FD, Webb P, Ducharme MB, Ramsay T, Kenny GP. A three557 compartment thermometry model for the improved estimation of changes in body heat content. 558 Am J Physiol Regul Integr Comp Physiol. 2007: 292: R167-175. 
Katz A, Ekberg K, Johansson BL, Wahren J. Diminished skin blood flow in Type I diabetes: evidence for non-endothelium-dependent dysfunction. Clin Sci (Lond). 2001: 101: 59-64.

561 Kenny GP, Dorman LE, Webb P, Ducharme MB, Gagnon D, Reardon FD, Hardcastle SG, Jay

562 O. Heat balance and cumulative heat storage during intermittent bouts of exercise. Med Sci

563 Sports Exerc. 2009: 41: 588-596.

564 Kenny GP, Jay O. Thermometry, calorimetry, and mean body temperature during heat stress.

565 Compr Physiol. 2013: 3: 1689-1719.

566 Kenny GP, Webb P, Ducharme MB, Reardon FD, Jay O. Calorimetric measurement of 567 postexercise net heat loss and residual body heat storage. Med Sci Sports Exerc. 2008: 40: 16295681636.

569 Khan F, Elhadd TA, Greene SA, Belch JJ. Impaired skin microvascular function in children, 570 adolescents, and young adults with type 1 diabetes. Diabetes Care. 2000: 23: 215-220.

571 King GL. The role of inflammatory cytokines in diabetes and its complications. J Periodontol. 572 2008: 79: 1527-1534.

573 Kohl HW, Blair SN, Paggenbarger RS, Macera CA, Kronenfeld JJ. A mail survey of physical 574 activity habits as related to measured physical fitness. Am J Epidemiol. 1988: 127: 1228-1239.

575 Limberg JK, Taylor JL, Dube S, Basu R, Basu A, Joyner MJ, Wehrwein EA. Role of the carotid 576 body chemoreceptors in baroreflex control of blood pressure during hypoglycaemia in humans.

577 Exp Physiol. 2014: 99: 640-650.

578 McCord JL, Halliwill JR. H1 and $\mathrm{H} 2$ receptors mediate postexercise hyperemia in sedentary and 579 endurance exercise-trained men and women. J Appl Physiol (1985). 2006: 101: 1693-1701.

580 McInnis NH, Journeay WS, Jay O, Leclair E, Kenny GP. 15 degrees head-down tilt attenuates 581 the postexercise reduction in cutaneous vascular conductance and sweating and decreases 582 esophageal temperature recovery time. J Appl Physiol (1985). 2006: 101: 840-847.

583 Menon RK, Grace AA, Burgoyne W, Fonseca VA, James IM, Dandona P. Muscle blood flow in 584 diabetes mellitus. Evidence of abnormality after exercise. Diabetes Care. 1992: 15: 693-695.

585 Nishi Y. Measurement of thermal balance in man. In: Cena K, Clark J, eds. Bioengineering 586 Thermal Physiology and Comfort. New York: Elsevier, 1981:29-39.

587 Parekh A, Lee CM. Heart rate variability after isocaloric exercise bouts of different intensities. 588 Med Sci Sports Exerc. 2005: 37: 599-605.

589 Penaz J. Photoelectric measurement of blood pressure, volume and flow in the finger. Digest 590 10th Int Conf Med Biol Eng. 1973: 104. 
591 Peyton PJ, Thompson B. Agreement of an inert gas rebreathing device with thermodilution and 592 the direct oxygen Fick method in measurement of pulmonary blood flow. J Clin Monit Comput. 593 2004: 18: 373-378.

594 Ramanathan NL. A New Weighting System For Mean Surface Temperature Of The Human 595 Body. J Appl Physiol. 1964: 19: 531-533.

596 Stapleton JM, Yardley JE, Boulay P, Sigal RJ, Kenny GP. Whole-body heat loss during exercise 597 in the heat is not impaired in type 1 diabetes. Med Sci Sports Exerc. 2013: 45: 1656-1664.

598 Wesseling KH, de Wit B, van der Hoeven GMA, van Goudoever J, Settels JJ. Physiocal, 599 calibrating finger vascular physiology for Finapres. Homeostasis. 1995: 36: 67-82.

600 Westerhof BE, Gisolf J, Karemaker JM, Wesseling KH, Secher NH, van Lieshout JJ. Time 601 course analysis of baroreflex sensitivity during postural stress. Am J Physiol Heart Circ Physiol. 602 2006: 291: H2864-2874.

603 Weston PJ, James MA, Panerai RB, McNally PG, Potter JF, Thurston H. Evidence of defective 604 cardiovascular regulation in insulin-dependent diabetic patients without clinical autonomic 605 dysfunction. Diabetes Res Clin Pract. 1998: 42: 141-148.

606 Weston PJ, Panerai RB, McCullough A, McNally PG, James MA, Potter JF, Thurston H, Swales 607 JD. Assessment of baroreceptor-cardiac reflex sensitivity using time domain analysis in patients 608 with IDDM and the relation to left ventricular mass index. Diabetologia. 1996: 39: 1385-1391.

609 Whitby JD, Dunkin LJ. Cerebral, oesophageal and nasopharyngeal temperatures. Br J Anaesth. 610 1971: 43: 673-676.

611 Yardley JE, Stapleton JM, Carter MR, Sigal RJ, Kenny GP. Is whole-body thermoregulatory 612 function impaired in type 1 diabetes mellitus? Curr Diabetes Rev. 2013: 9: 126-136. 
614 Table 1. Participant characteristics presented for Controls and individuals with Type 1 Diabetes 615 (T1DM).

616

\begin{tabular}{rcc}
\hline & Control & T1DM \\
\hline Age (years) & $23.5 \pm 2.9$ & $22.3 \pm 4.7$ \\
Height $(\mathrm{cm})$ & $177 \pm 10$ & $178 \pm 8$ \\
Body Mass $(\mathrm{kg})$ & $79.1 \pm 15.6$ & $81.8 \pm 15.8$ \\
Body surface area $\left(\mathrm{m}^{2}\right)$ & $1.97 \pm 0.23$ & $1.99 \pm 0.23$ \\
$\mathrm{VO}_{2 \max }\left(\mathrm{L} \cdot \mathrm{min}^{-1}\right)$ & $3.4 \pm 0.7$ & $3.3 \pm 0.7$ \\
$\mathrm{VO}_{2 \max }\left(\mathrm{mL} \cdot \mathrm{kg}^{-1} \cdot \mathrm{min}^{-1}\right)$ & $45.3 \pm 2.4$ & $42.7 \pm 6.9$ \\
Baecke Score & $4.8 \pm 2.4$ & $4.8 \pm 2.9$ \\
Kohl's Score $\left(\mathrm{met}^{-1} \cdot \mathrm{hreek}^{-1}\right)$ & $60.5 \pm 22.7$ & $55.4 \pm 38.8$ \\
$\mathrm{HbA}(\mathrm{c})$ & & $8.5 \pm 0.4$ \\
Duration of Diabetes (years) & N/A & $8.4 \pm 2.9$ \\
\hline
\end{tabular}

617 N/A, not applicable. $\mathrm{VO}_{2 \max }$, maximal oxygen consumption. HbA1c, Hemoglobin $\mathrm{A}_{1 c}$. Values are 618 mean \pm standard error. No differences were found between groups for any variables $(\mathrm{P}>0.05)$.

619 The same participants were used as in our previous study (Carter et al. 2014). 
621 Table 2. Cardiovascular responses (cardiac output, stroke volume, heart rate, total peripheral 622 resistance, and mean arterial pressure) at baseline and at 10-minute intervals during recovery.

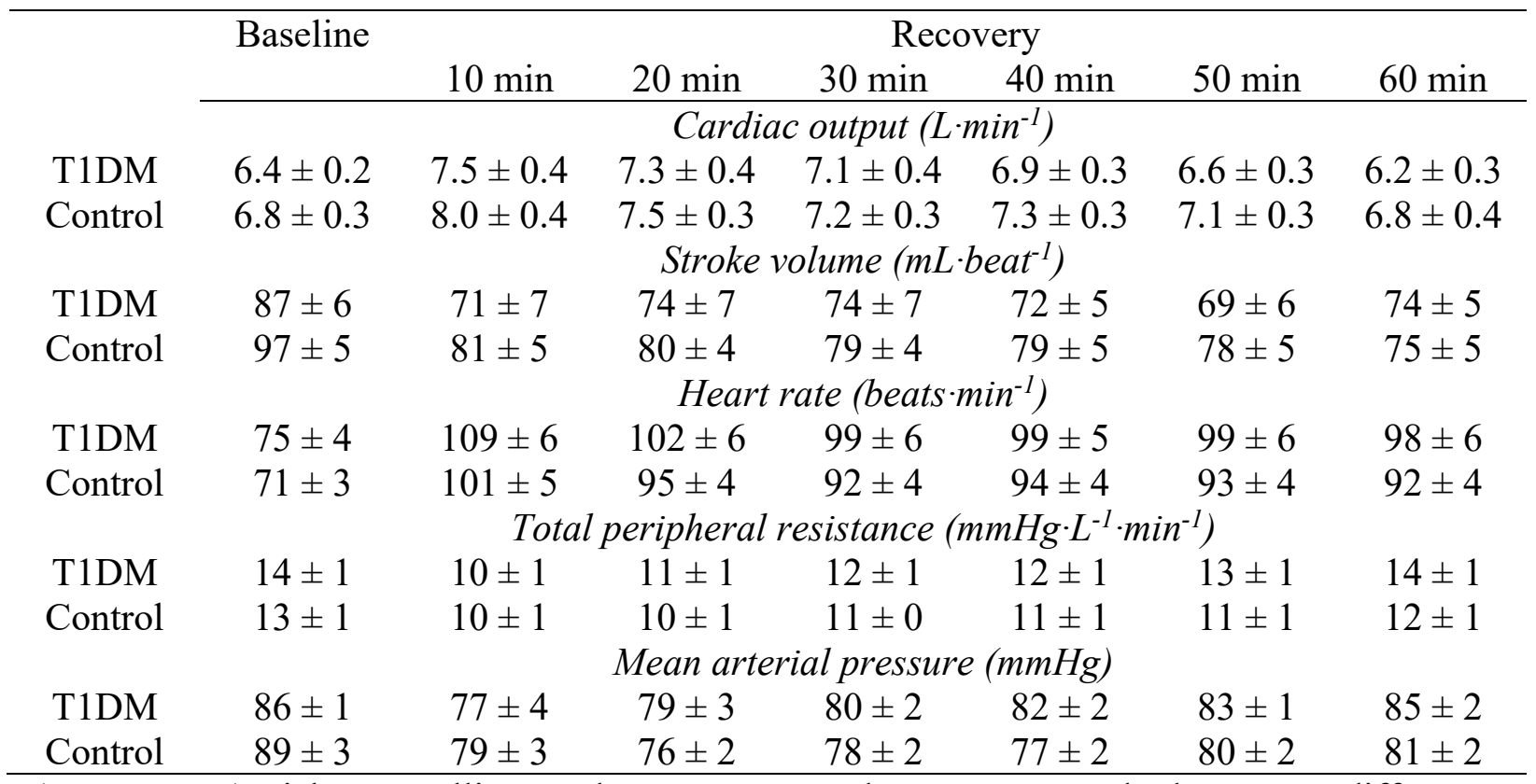

623 T1DM, Type 1 Diabetes Mellitus. Values are presented as mean \pm standard error. No differences 624 were found between groups $(\mathrm{P}>0.05)$. 
626 Table 3. Venous blood glucose concentrations, plasma osmolality, and changes in plasma 627 volume at baseline, end of exercise (End-Ex), and at minutes 30 and 60 of recovery.

\begin{tabular}{|c|c|c|c|c|}
\hline & \multirow{2}{*}{ Baseline } & \multirow{2}{*}{ End-Ex } & \multicolumn{2}{|c|}{ Recovery } \\
\hline & & & $30 \mathrm{~min}$ & $60 \mathrm{~min}$ \\
\hline & \multicolumn{4}{|c|}{ Venous blood glucose $\left(\mathrm{mmol} \cdot \mathrm{L}^{-1}\right)$} \\
\hline T1DM & $9.9 \pm 1.0^{*}$ & $6.1 \pm 0.8$ & $7.3 \pm 0.9$ & $7.6 \pm 0.8$ \\
\hline \multirow[t]{2}{*}{ Control } & $5.3 \pm 0.2$ & $5.1 \pm 0.2$ & $5.9 \pm 0.4$ & $5.7 \pm 0.5$ \\
\hline & \multicolumn{4}{|c|}{ Plasma osmolality (mosmol $\cdot \mathrm{kgH}_{2} \mathrm{O}^{-1}$ ) } \\
\hline T1DM & $288 \pm 3$ & $297 \pm 2$ & $293 \pm 2$ & $296 \pm 2$ \\
\hline \multirow[t]{2}{*}{ Control } & $289 \pm 1$ & $300 \pm 2$ & $295 \pm 2$ & $295 \pm 1$ \\
\hline & \multicolumn{4}{|c|}{ Change in plasma volume (\%) } \\
\hline T1DM & & $-11 \pm 2$ & $-3 \pm 2$ & $-5 \pm 1$ \\
\hline Control & & $-12 \pm 2$ & $-6 \pm 1$ & $-6 \pm 1$ \\
\hline
\end{tabular}

628 Values are mean \pm standard error. *, T1DM significantly greater venous blood glucose

629 concentration at baseline compared to Control $(\mathrm{P}<0.05)$.

630

631

632

633

634 
Figure 1. Experimental protocol timeline. Ambient conditions were $35^{\circ} \mathrm{C}$ and $20 \%$ relative humidity. Downward arrow indicates a point at which cardiac output was measured (i.e., at baseline and every $10 \mathrm{~min}$ during recovery). Thermoregulatory variables were measured continuously. *, data from exercise has been discussed previously in detail (Carter et al. 2014). $\mathrm{BD}$, blood draws were taken at baseline, end of exercise, and at minutes 30 and 60 of recovery.

Figure 2. Esophageal ( $T_{\text {eso }}$, panel $\left.A\right)$, mean skin ( $T_{\text {skin, }}$ panel $\left.B\right)$, and rectal $\left(\mathrm{T}_{\text {rec, }}\right.$, panel $\left.C\right)$ temperatures at baseline (Rest), end of exercise (End-Ex), and at 10-minute intervals throughout recovery for participants with Type 1 Diabetes Mellitus (T1DM) and healthy Controls (Control). Values are mean \pm standard error. *, T1DM significantly greater than Control $(\mathrm{P}<0.05)$.

Figure 3. Cutaneous vascular conductance (CVC) presented as percentage of maximum (\% Max) at the forearm (panel A) and upper back (panel B) at baseline (Rest), end of exercise (End-Ex), and at 10-minute intervals throughout recovery for participants with Type 1 Diabetes Mellitus (T1DM) and healthy Controls (Control). Values are mean \pm standard error. No differences were found between groups $(\mathrm{P}>0.05)$.

Figure 4. Local sweat rate (LSR) presented at the forearm (panel A), upper back (panel B), and chest (panel C) at baseline (Rest), end of exercise (End-Ex), and at 10-minute intervals throughout recovery for participants with Type 1 Diabetes Mellitus (T1DM) and healthy Controls (Control). Values are mean \pm standard error. *, T1DM significantly lower than Control $(\mathrm{P}<0.05)$.

Figure 5. Baroreflex sensitivity (panel A) and the magnitude of hypotension (panel B) at baseline (Rest) and at 10-minute intervals throughout recovery for participants with Type 1 Diabetes Mellitus (T1DM) and healthy Controls (Control). Values are mean \pm standard error. *, T1DM significantly different from Control $(\mathrm{P}<0.05)$. 
667 Figure 1.

668

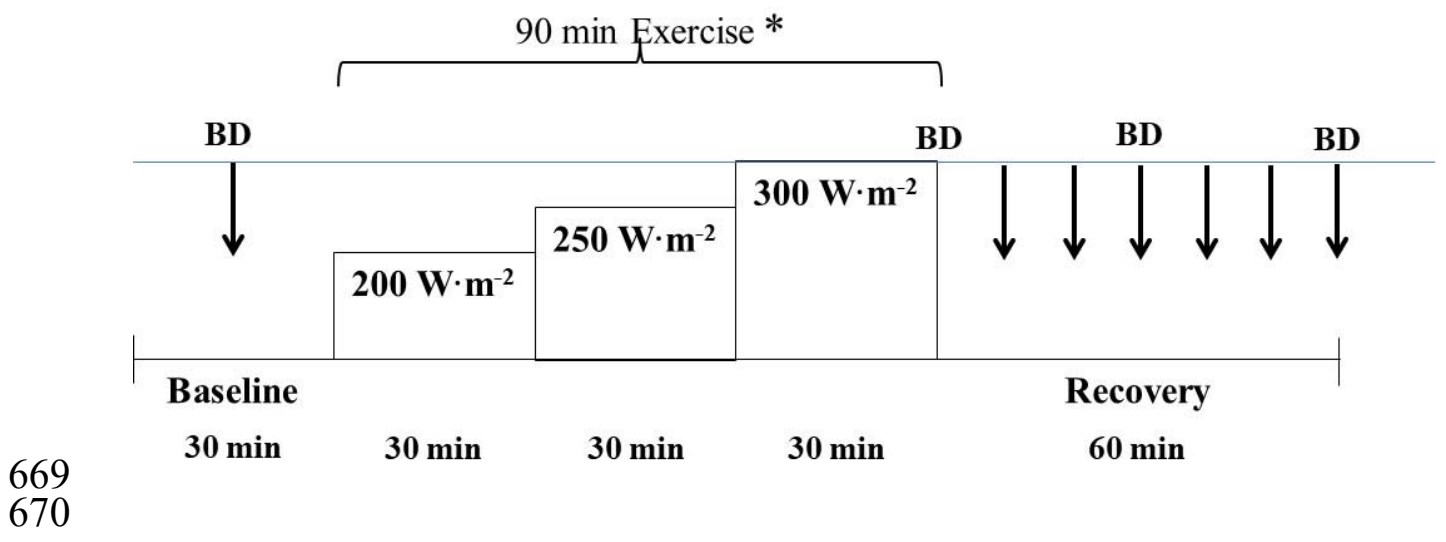


$671 \quad$ Figure 2.

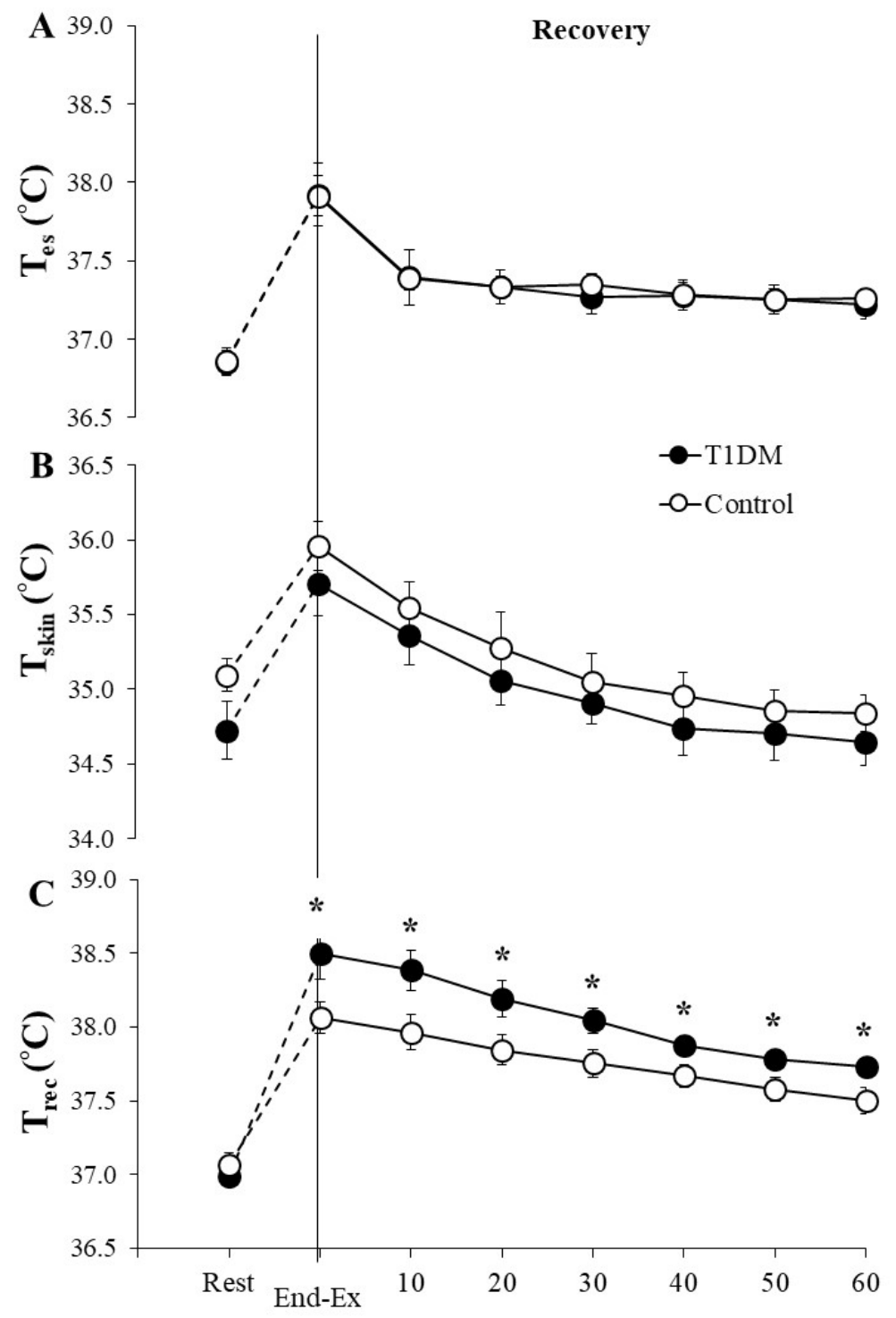

672

673 
$674 \quad$ Figure 3.

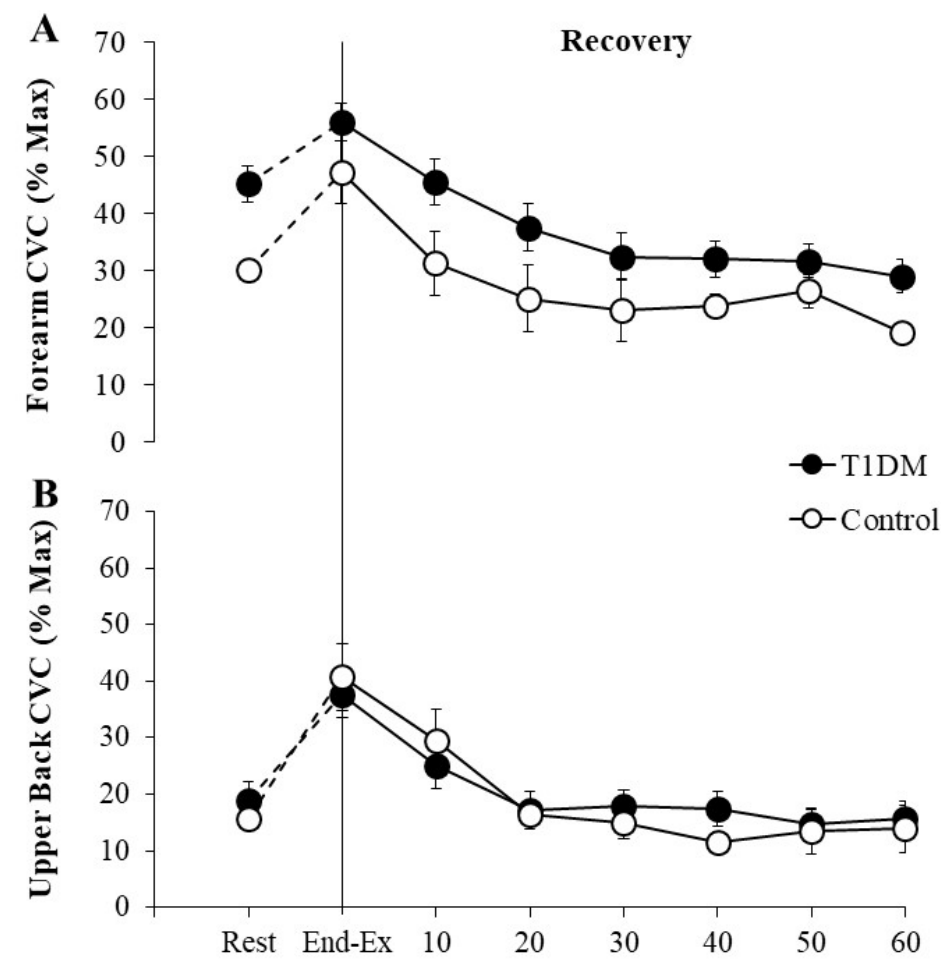

675

676 
$677 \quad$ Figure 4.

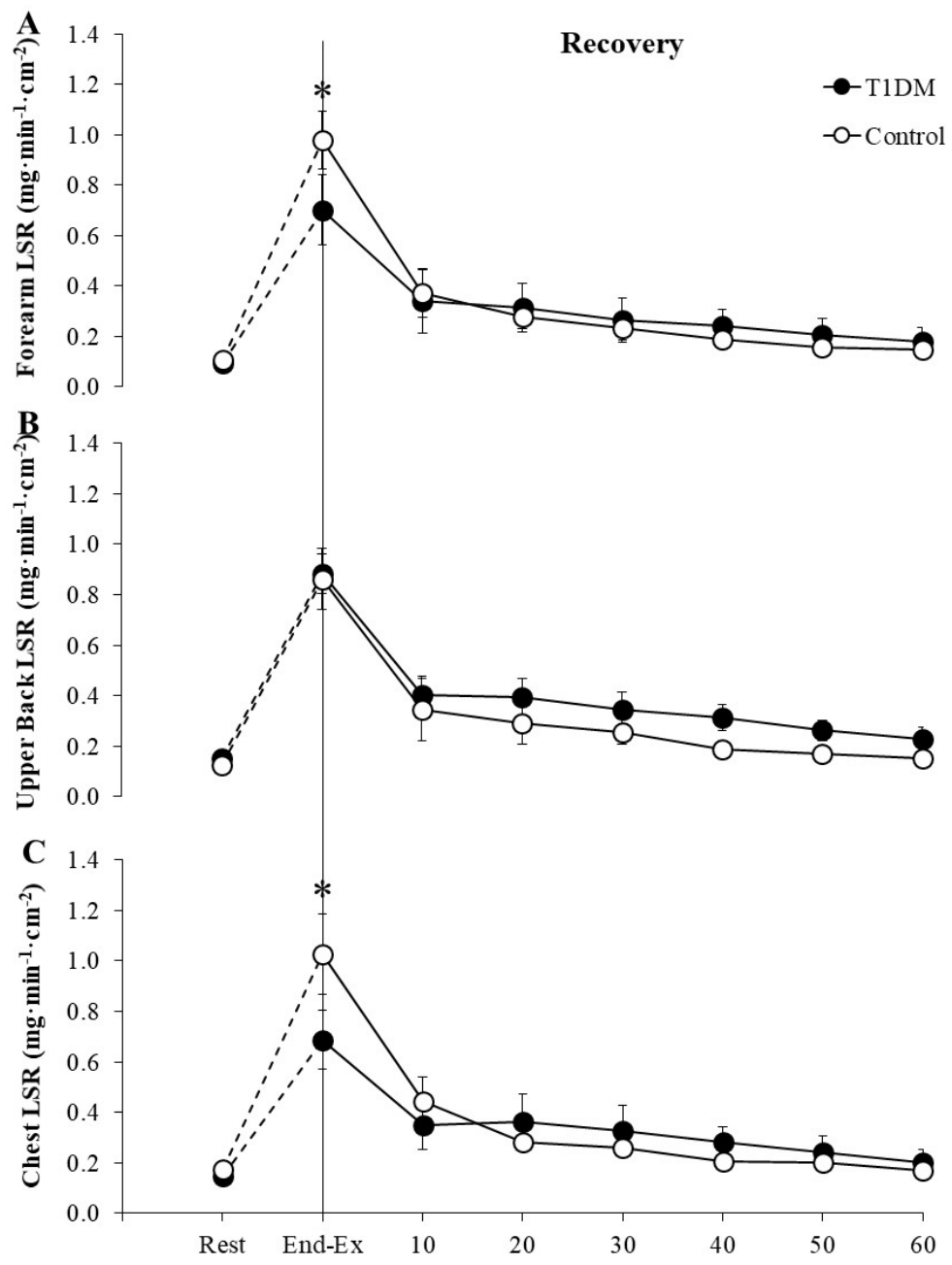

678

679 
$680 \quad$ Figure 5.
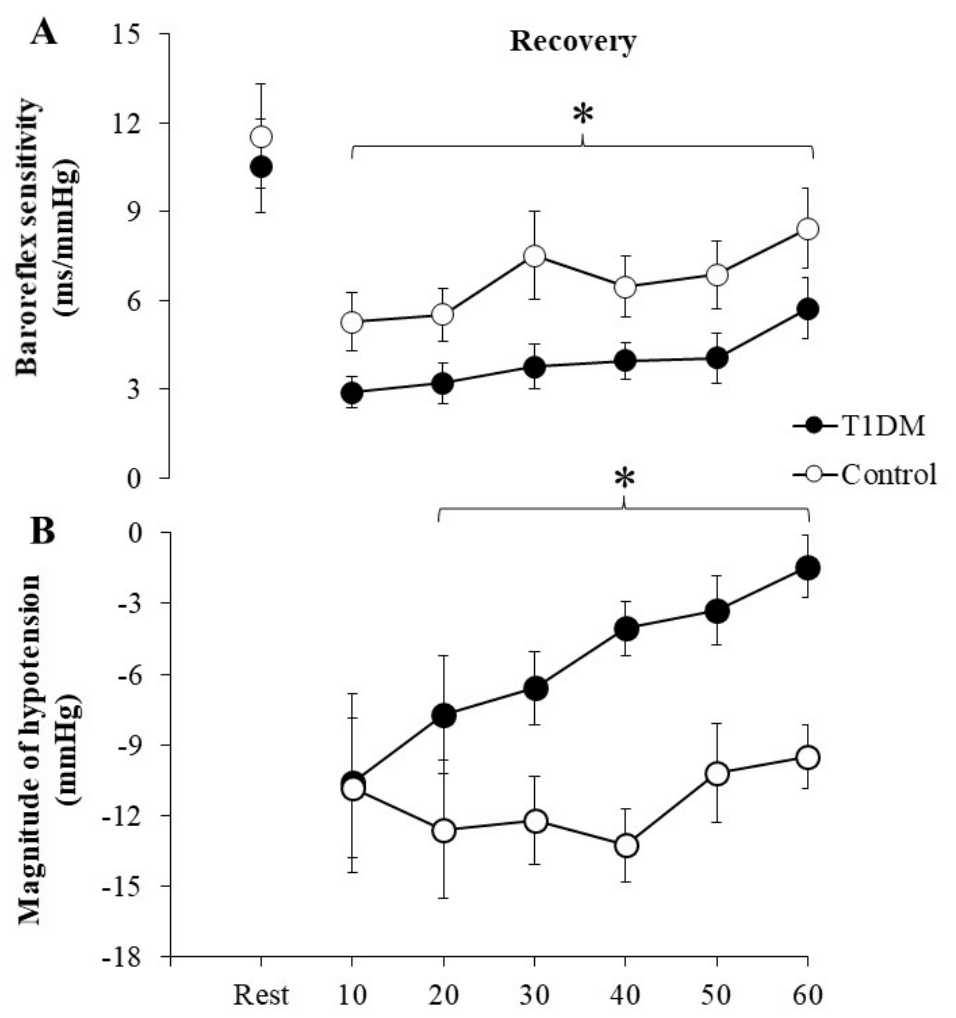